\title{
Sorbent Regeneration by Cascade Cyclone Calciner in a Pilot-Scale Calcium Looping Carbon Capture System
}

\author{
Y. C. Chou, W. C. Chen, H. W. Hsu, and H. P. Wan
}

\begin{abstract}
The aim of this study was to design and operate a cascade cyclone calciner for sorbent regeneration in a pilot-scale calcium looping carbon capture process. The calciner was designed on the basis of mass and energy balance analysis of a $500 \mathrm{~kW}_{\text {th }}$ system. Effects of flue gas recirculation (FGR), and fuel feeding rate on the sorbent calcination efficiency were investigated. Calculation results determined the capacity of the diesel-fired oxy-combustor applied in the calciner and the geometric dimension of the $500 \mathrm{kWth}$ calciner. Experimental results indicated that the flue gas recirculation stabilized the temperature distribution inside calciner. Approximately $200^{\circ} \mathrm{C}$ temperature gradient through the cascade cyclone calciner was achieved in this study. Both the temperature distribution of flue gas and the migration path of sorbents inside calciner affected the calcination efficiency. The enhancement in flue gas recirculation rate provided more flue gas inventory for sorbent transportation and the increase in fuel feeding rate offered more energy for sorbent calcination. The increases of fuel feeding rate from $46 \mathrm{~L} / \mathrm{h}$ to $50 \mathrm{~L} / \mathrm{h}$ and the flue gas recirculation rate from $3380 \mathrm{CMH}$ to $3870 \mathrm{CMH}$ led to almost 4.6 times enhancement in the sorbent calcination efficiency. The calcination efficiency higher than $80 \%$ would be realized for experiments using fuel feeding rates higher than $\mathbf{5 0}$ L/h.
\end{abstract}

Index Terms-Calcium looping carbon capture process, cascade cyclone calciner, flue gas recirculation, calcination efficiency.

\section{INTRODUCTION}

The calcium looping technology has been regards as one of the promising post-combustion $\mathrm{CO}_{2}$ capture processes because of its characteristics of nontoxic sorbent, high $\mathrm{CO}_{2}$ capture capacity, high-quality heat recovery, and low sorbent cost. Fig. 1 shows the schematic diagram of the calcium looping process. $\mathrm{CaO}$ reacts with gaseous $\mathrm{CO}_{2}$ contained in flue gas to carry out the exothermic carbonation reaction $\left(\sim 650^{\circ} \mathrm{C}\right)$ in carbonator, producing calcium carbonate and a $\mathrm{CO}_{2}$ lean stream. The carbonated sorbent is transferred to the calciner for sorbent regeneration $\left(>850^{\circ} \mathrm{C}\right)$. The regenerated sorbent is then transported back to the carbonator for following carbonation reaction. The carbonation and calcination are thermodynamically spontaneous and reversible reactions, and the extent of these reactions is dependent on the $\mathrm{CO}_{2}$ partial pressure and the reaction temperature.

Manuscript received September 30, 2017; revised January 24, 2018. This work was supported by the Bureau of Energy, Ministry of Economic Affairs of Taiwan.

The authors are with the Green Energy and Environment Research Laboratories, Industrial Technology Research Institute, Taiwan (e-mail: chouyc@itri.org.tw).
Shimizu [1] made the beginning of applying carbonation-calcination process into $\mathrm{CO}_{2}$ mitigation technology in a dual fluidized bed system. Thereafter, numerous researchers have gradually dedicated their studies to investigate certain aspects of this process in laboratory-scale experiments, including thermodynamic, kinetic, reaction mechanism, sorbent properties, and technical feasibility of this process. Recently, the development of calcium looping technology is moving on to deal with scale-up issues including all industrial constraints and engineering tasks [2]-[5]. Industrial Technology Research Institute (ITRI) is one of active groups to demonstrate the operating feasibility of calcium looping process under realistic conditions at a kilowatt-scale and megawatt-scale pilot plants. Their $3 \mathrm{~kW}_{\text {th }}$ system consists of a bubbling fluidized bed (BFB) carbonator and a rotary kiln calciner connected with a pneumatic pipe transport system [4]. A 100-hour continuous operation demonstrated that the $\mathrm{CO}_{2}$ capture level of this system was higher than $85 \%$. Inspired by this experimental results, a $1.9 \mathrm{MW}_{\text {th }}$ pilot-scale system has been constructed in Heping, Taiwan Cement Company (TCC), to capture $\mathrm{CO}_{2}$ "in situ" from TCC's cement process. The operating of this pilot plant has been extended for more than $1700 \mathrm{hrs}$, including $700 \mathrm{hrs}$ in $\mathrm{CO}_{2}$ capture with a $\mathrm{CO}_{2}$ capture efficiency of $50-85 \%$ [5].

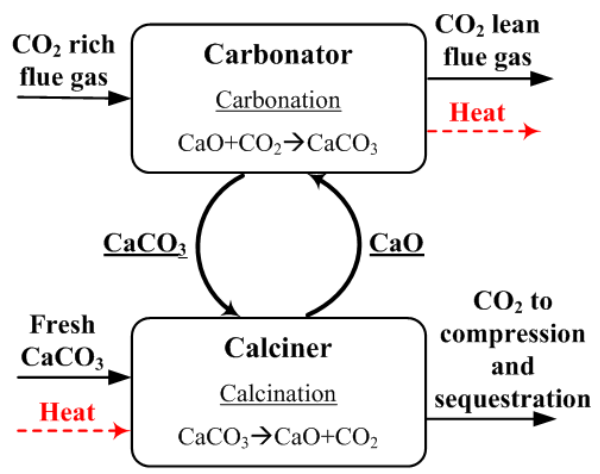

Fig. 1. The schematic diagram of the calcium looping process.

The major challenges for commercializing calcium looping technology are the sorbent decay after several carbonation-calcination cycles and the high energy requirement for sorbent regeneration. The approaches for enhancing sorbent recyclability could be categorized into three aspects: synthesis of $\mathrm{CaO}$ sorbent from inorganic or organometallic precursors [6] and [7], incorporation of dopant or inert stabilizer with calcium-based sorbents [8] and [9], and sorbent reactivation through additional processing [10]-[12]. Strategies for promoting heat utilization included applying oxy-fuel combustion [3] and [13], implementing district energy supply (DES) system [14], and promoting the 
solid-gas contact pattern inside reactors [15] and [16]. In this study, a calciner in the configuration of cascade cyclone was designed to greatly promote the solid-gas contact pattern corresponding to improve heat utilization in a $500 \mathrm{~kW}_{\text {th }}$ pilot-scale calcium looping system. A diesel-fired oxy-combustor integrating with flue gas recirculation (FGR) provided the heat for sorbent regeneration in the calciner. The burner capacity of this system was calculated from the mass and energy balance analysis of a $500 \mathrm{~kW}_{\text {th }}$ system. Effects of flue gas recirculation (FGR), and fuel feeding rate on the sorbent calcination efficiency were examined. The temperature distribution inside calciner was measured to discuss the possible sorbent migration path inside calciner as well as sorbent calcination efficiency.

\section{MATERIALS AND EXPERIMENTS}

The sorbent used in this study was the limestone manufactured from the quarries at Suao Township, Ilan County (Taiwan). The composition of the calcined limestone was $54.86 \% \mathrm{CaO}$ and $42.7 \%$ loss on ignition. The size distribution of the original limestone measured by a sieve shaker was in the range of 350 to $900 \mu \mathrm{m}$, (the mean diameter $\sim 668 \mu \mathrm{m}$ ).

The experimental campaign presented in this work was conducted in a $500 \mathrm{~kW}_{\text {th }}$ cascade cyclone calciner that provided sorbent for carbon capture from a cement process, property of Taiwan Cement Company (TCC) which is located in Heping (Taiwan). Fig. 2 shows the schematic diagram of the $500 \mathrm{~kW}_{\text {th }}$ cascade cyclone calciner. The calciner consists of a primary riser (Riser_Com), four cyclone-equipped risers (C1/Riser 1, C2/Riser 2 , C3/Riser 3 and C4/Riser 4), a high efficiency cyclone (C0) and an oxy-fuel combustion system. Each riser is equipped with thermocouple to monitor the temperature profile inside the calciner, as T1 T5 shown in Fig. 2. The height of this facility is $19 \mathrm{~m}$, and the diameter of each riser was designed on the basis of adaptive gas velocity through these vessels. All the elements were refractory lined or thermally insulated to minimize heat losses.

A diesel-fired oxy-combustor with flue gas recycling provided high-temperature flue gas for sorbent regeneration and transportation in the calciner, resulting in highly pure $\mathrm{CO}_{2}$ stream separated out from the calcination process. The quantity of heat was controlled by a burner skid that adjusted the amounts of diesel and oxygen in the combustor. Flue gas produced from the combustor flowed into the primary riser (Riser_Com) and was separated by $\mathrm{C} 1$ cyclone. The separated stream leaved from the top of cyclone was then transported to the following risers and cyclones. The transportation pathway of the flue gas insider the calciner was delineated by the solid line in Fig. 2. A fraction of the exhausted flue gas was recirculated to reduce the oxygen fraction in the burner for temperature control and to increase the gas velocity in the risers and cyclones for solid transportation. The flue gas recirculation rate was controlled by an induced draft fans (ID fan).

Fresh sorbent was continuously delivered to the Riser 3 of the calciner by a rotary valve when the temperature profile inside the calciner was considered to be steady. The sorbent was pneumatically transported to $\mathrm{C} 1$ cyclone in co-current flow with the flue gas; meanwhile, rapid heat exchange could be observed during the solid conveyance. The sorbent collected from C4 cyclone was dropped to Riser 2 for further heat exchange and calcination. The sorbent transportation inside the calciner was shown by the red dashed line in Fig. 2. The calcined sorbent was separated by a 70-mesh sieve (cut size $210 \mu \mathrm{m})$. The calcination efficiency of the sieved samples were measured by a SETARAM SETSYS Evolution thermogravimetric analyzer (TGA).

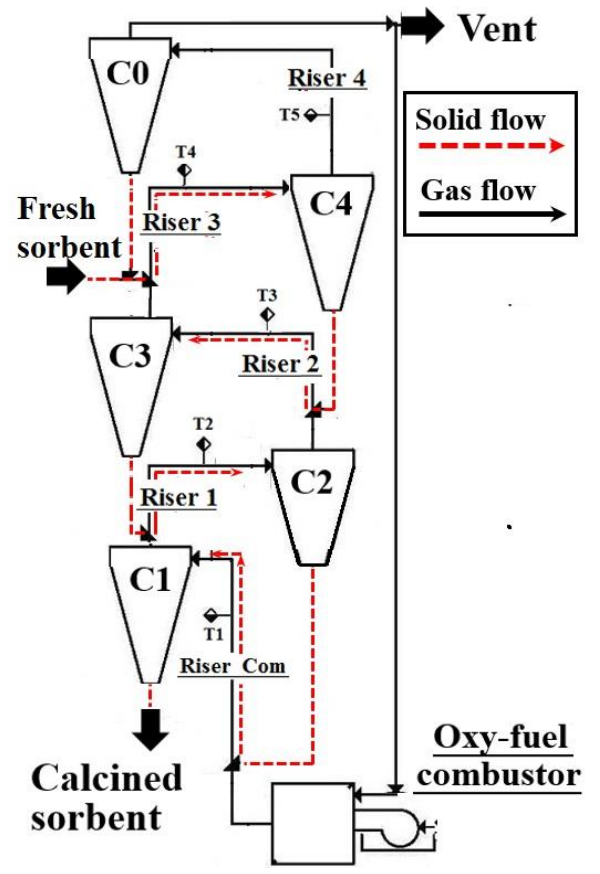

Fig. 2. Schematic diagram of a $500 \mathrm{~kW}_{\text {th }}$ cascade cyclone calciner.

\section{RESULTS AND DISCUSSION}

\section{A. Design of the $500 \mathrm{~kW}_{\text {th }}$ Cascade Cyclone Calciner}

The calciner in the configuration of cascade cyclone was designed to greatly promote the solid-gas contact pattern corresponding to improve heat utilization in the reactor. Table I shows the mass and energy balance analysis of a $500 \mathrm{~kW}_{\text {th }}$ calcium looping process. Both the conversions in calciner and carbonator were assumed to be $80 \%$. The sorbent flow rate from a calciner contained $\mathrm{CaO}$ in the range of 0.96 ton $/ \mathrm{h}$ and $1.29 \mathrm{ton} / \mathrm{h}$, and $\mathrm{CaCO}_{3}$ in the range of 0.24 ton $/ \mathrm{h}$ and $0.32 \mathrm{ton} / \mathrm{h}$ when the molar calcium to carbon ratio was elevated from 6 to 8 . The carbonation reaction yielded 0.29 ton/h calcium carbonate $\left(\mathrm{CaCO}_{3}\right)$, resulting in the flow rate of solid mixture leaving the carbonator operated between 1.33 and 1.73 ton $/ \mathrm{h}$. The sensible heat for heating the $\mathrm{CaO} / \mathrm{CaCO}_{3}$ mixture to calcination temperature $\left(850^{\circ} \mathrm{C}\right)$ and the latent heat for calcination reaction could be calculated subsequently. The theoretical heat demand for achieving $80 \%$ calcination efficiency was between $27540 \mathrm{~kJ} / \mathrm{min}$ and $35309 \mathrm{~kJ} / \mathrm{min}$. The burner capacity applied in the calciner was then determined on the basis of theoretical heat demand and an estimated heat exchange efficiency in the claciner. The diesel consumption and flue gas flow rate from a diesel-fired oxy-combustor could be calculated accordingly. 
The main body of $500 \mathrm{~kW}_{\text {th }}$ calciner was consists of risers and cyclones. Fig. 3 reveals the flowchart for calculating geometric dimension of the $500 \mathrm{~kW}_{\text {th }}$ calciner. In the calculation, the solid and flue gas flow rates was obtained from the mass and energy balance analysis. The gas flow rate demands in the calciner and from flue gas recirculation were evaluated according to the solid-gas ratio in pneumatic conveying reported in the authors' previous study [15]. The riser diameters came from gas velocity assumptions in the risers, while the gas velocity in each riser and cyclone was calibrated by an estimated temperature distribution inside calciner. The cyclone dimensions, including height of the conical and cylindrical sections, cone-tip diameter, vortex finder diameter, and vortex finder length, were determined on the basis of geometrical ratios of cyclones. The photograph of the $500 \mathrm{~kW}_{\text {th }}$ cascade cyclone calciner is shown in Fig. 4.

TABLE I: THE MASS AND ENERGY BALANCE ANALYSIS OF A 500KW CALCIUM LOOPING PROCESS

\begin{tabular}{cccc}
\hline Calcium to carbon ratio (-) & 6 & 7 & 8 \\
\hline $\mathrm{CaO}$ produced from calciner (ton/h) & 0.96 & 1.13 & 1.29 \\
$\mathrm{CaCO}_{3}$ produced from calciner (ton/h) & 0.24 & 0.28 & 0.32 \\
\hline $\mathrm{CaCO}_{3}$ produced from carbonator (ton/h) & 0.29 & \\
Residual CaO after Carbonation (ton/h) & 0.80 & 0.96 & 1.13 \\
Sorbent flow rate in the calciner (ton/h) & 1.33 & 1.53 & 1.73 \\
\hline Sensible heat (kJ/min) & 15,003 & 17,934 & 20,864 \\
Latent heat (kJ/min) & 12,537 & 13,491 & 14,444 \\
Heat demand for calcination* $(\mathrm{kJ} / \mathrm{min})$ & 27,540 & 31,424 & 35,309 \\
\hline Sorbent calcination efficiency 80\% & & &
\end{tabular}

*Sorbent calcination efficiency $80 \%$

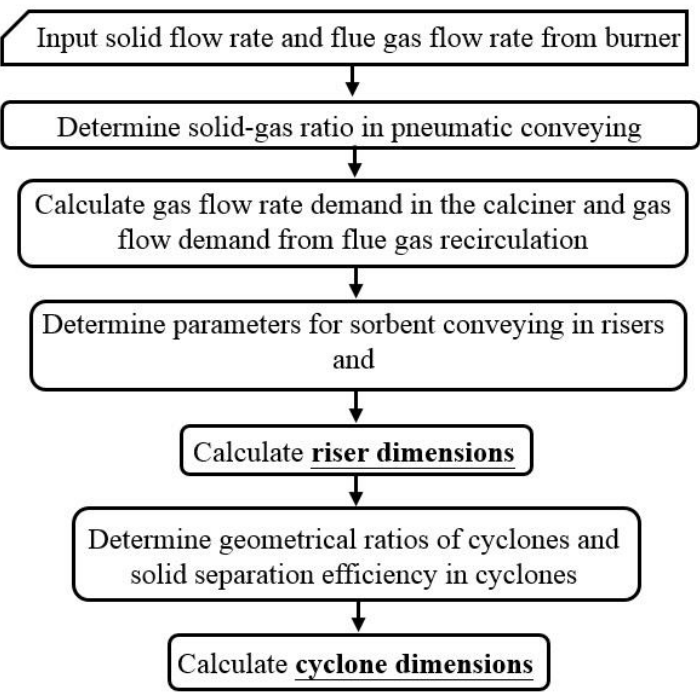

Fig. 3. Flowchart for calculation of geometric dimension of the 500kWth calciner.

\section{B. Operation of the $500 \mathrm{~kW}_{\text {th }}$ Cascade Cyclone Calciner}

A diesel-fired oxy-combustor with an integrated flue gas recirculation system provided the heat for sorbent regeneration in the cascade cyclone calciner. Fig. 5 shows the influence of flue gas recirculation (FGR) on the temperature distribution inside calciner. The flue gas temperature was significantly dropped from $795^{\circ} \mathrm{C}$ (T1) to $433^{\circ} \mathrm{C}$ (T2) in the primary riser (Riser Com) and Riser 1 and then gradually declined to $235^{\circ} \mathrm{C}$ at the downstream of riser 4 (T5) when experiments was conducted without flue gas recirculation. The remarkable temperature gradient through this calciner is because that high quality heat generated from oxy-fuel combustion was accumulated in the burner and primary riser. The flue gas recirculation suppressed the temperature gradient dramatically because the recirculated flue gas reduced oxygen fraction in the burner for temperature control and increased gas inventory in the calciner for heat transfer toward downstream of the calciner. The stable temperature distribution through the calciner $\left(<200^{\circ} \mathrm{C}\right)$ offered higher heat utilization efficiency in this system. Moreover, Fig. 5 also illustrates the calciner temperature distribution for experiments conducted under various fuel feeding rates. Higher fuel feeding rate provided more energy for sorbent calcination, resulting in the higher temperature distribution. Experimental results indicated that the temperatures in the primary riser (Riser_Com) and the first cyclone-equipped riser $(\mathrm{C} 1 / \mathrm{Riser} 1)$ reached the calcination temperature when the fuel feeding rate was higher than $55 \mathrm{~L} / \mathrm{h}$.

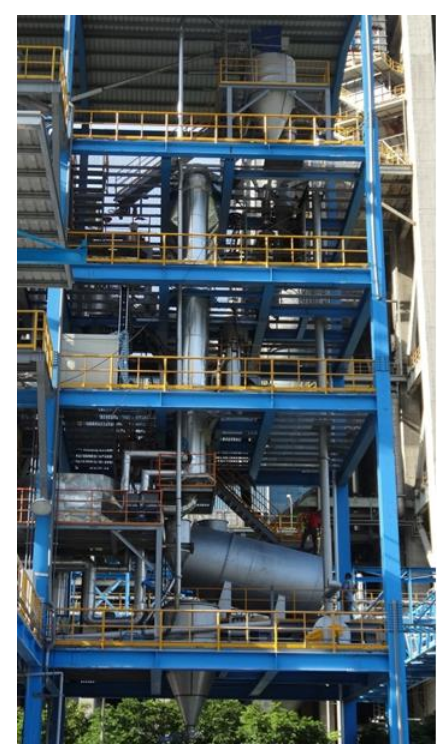

Fig. 4. The photograph of the $500 \mathrm{~kW}$ th cascade cyclone calciner.

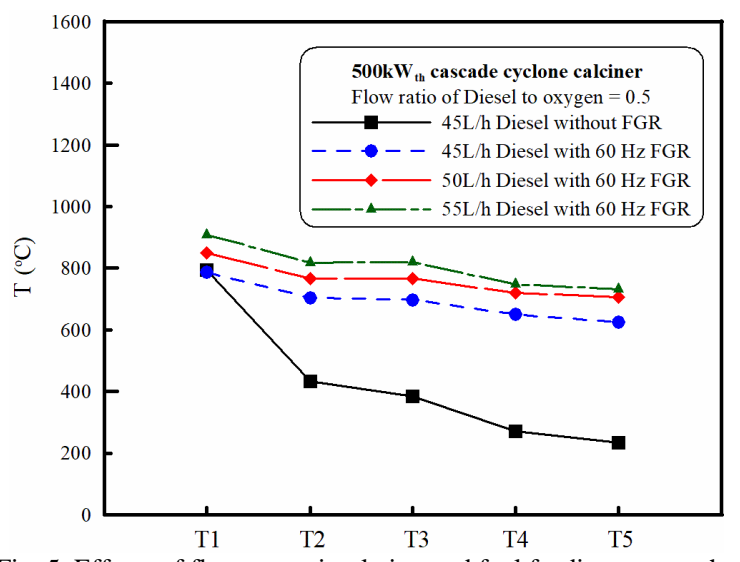

Fig. 5. Effects of flue gas recirculation and fuel feeding rate on the temperature distribution inside calciner.

Fig. 6 depicts the temperature distribution inside calciner for experiments without feeding sorbent and with 1.8 ton/h sorbent feeding rate. Two significant temperature drops were observed at T2 and T4 after feeding 1.8 ton/h sorbent into the 
calciner. This is because the mass flow ratio of sorbent to flue gas under this operating condition was two-fold higher than the design value, leading to most of feeding sorbents did not follow the solid transportation pathway revealed in Fig. 2. These sorbents were directly dropped to $\mathrm{C} 3$ and $\mathrm{C} 1$ cyclones and then fell out of the calciner. This phenomenon is defined as short-circuit sorbent transportation pathway in this system. Extreme hear exchange observed during the extraordinary solid transport caused the significant temperature drops shown in Fig. 6.

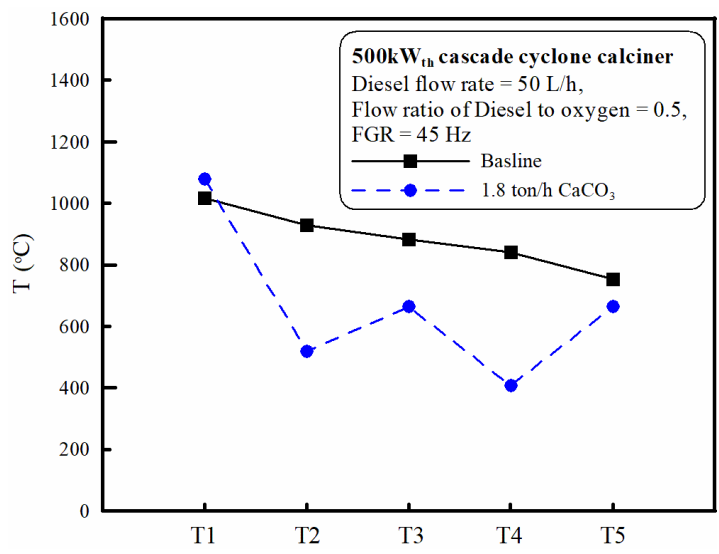

Fig. 6. The temperature distribution inside calciner under the sorbent feeding rate of $1.8 \mathrm{ton} / \mathrm{h}$.

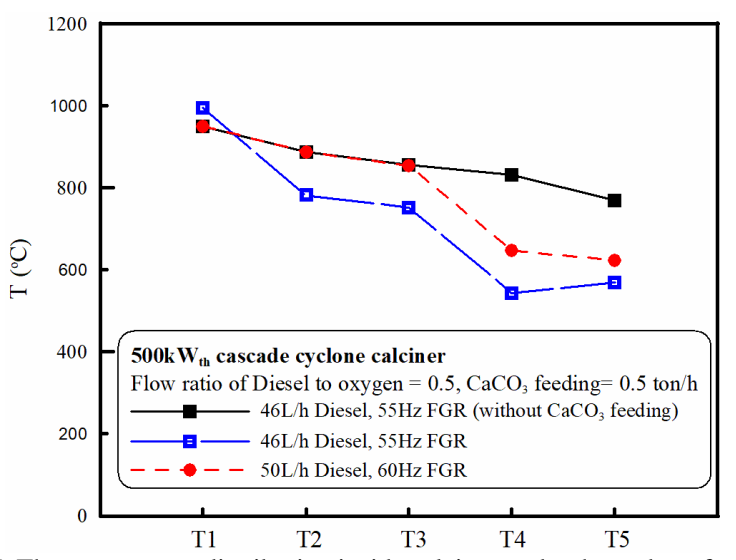

Fig. 7. The temperature distribution inside calciner under the sorbent feeding rate of $0.5 \mathrm{ton} / \mathrm{h}$.

Fig.7 shows the temperature distribution inside calciner for experiments calcined 0.5 ton $/ \mathrm{h} \mathrm{CaCO}_{3}$. To compare the temperature distribution for calcination using $46 \mathrm{~L} / \mathrm{h}$ diesel and $55 \mathrm{~Hz}$ FGR (3380 CMH flue gas), the sorbent feeding led to temperature increase in the primary riser (Riser_Com) possibly because the back pressure induced by sorbent feeding retarded the heat transfer toward the downstream of the calciner. The slight temperature drop (T2) in the Riser 1 implies that part of feeding sorbent still followed the short-circuit pathway. The composition of calcined sorbent was 4.24 mol. $\% \mathrm{Ca}(\mathrm{OH})_{2}, 43.66 \mathrm{~mol} \% \mathrm{CaCO}_{3}$, and 52.10 mol. \% $\mathrm{CaO}$, corresponding to $16.20 \%$ calcination efficiency. The other operating condition providing more energy $(50 \mathrm{~L} / \mathrm{h}$ diesel) and higher gas inventory $(60 \mathrm{~Hz}$ FGR, corresponding to $3870 \mathrm{CMH}$ flue gas) for sorbent calcination. The temperature distribution shown in Fig. 7 revealed that the temperatures in the primary riser (Riser_Com) and two stages cyclone-equipped riser (C1/Riser 1 and $\mathrm{C} 2 / \mathrm{Riser} 2)$ were suitable for sorbent calcination. The significant temperature drop was only observed in the Riser 3 (T4) due to the fresh sorbent feeding, indicated that the short-circuit phenomenon may be no longer the limiting factor for sorbent calcination. The major composition in this calcined sorbent was calcium oxide (71.68 mol.\%). The calcination efficiency was $74.48 \%$. The calcination efficiency for experiments conducted under this condition was almost 4.6 times higher than that under 46 $\mathrm{L} / \mathrm{h}$ diesel and $55 \mathrm{~Hz}$ FGR. The calcination efficiencies higher than $80 \%$ would expect to be achieved for experiments using fuel feeding rates higher than $50 \mathrm{~L} / \mathrm{h}$.

\section{CONCLUSIONS}

The design and operation of a cascade cyclone calciner were conducted for sorbent regeneration in a $500 \mathrm{~kW}_{\text {th }}$ calcium looping carbon capture process. The mass and energy balance analysis indicated that the sorbent circulating rate in this system was in the range of 1.5 and 1.96 ton/h, while the heat demand for sorbent regeneration was between $28312 \mathrm{~kJ} / \mathrm{min}$ and $37944 \mathrm{~kJ} / \mathrm{min}$. Gas velocities in the risers and cyclones determined the dimensions of cascade cyclone calciner. The recirculated flue gas offered stable temperature distribution through the calciner $\left(<200^{\circ} \mathrm{C}\right)$ as well as higher heat utilization efficiency in this system. The inappropriate mass flow ratio of sorbent to flue gas induced short-circuit phenomenon inside calciner. The sorbent calcination efficiency was significantly improved by correcting the solid transportation pathway inside calciner. The calcination efficiency higher than $80 \%$ would be realized for experiments using fuel feeding rates higher than $50 \mathrm{~L} / \mathrm{h}$ with $60 \mathrm{~Hz}$ FGR.

\section{REFERENCES}

[1] T. Shimizu, T. Hirama, H. Hosoda, K. Kitano, M. Inagaki, and K Tejima, "A twin fluid-bed reactor for removal of $\mathrm{CO}_{2}$ from combustion processes,” Chem. Eng. Res. Design, vol. 77, no. 1, pp. 62-68, 1999.

[2] J. Ströhle, M. Junk, J. Kremer, A. Galloy, and, B. Epple, "Carbonate looping experiments in a $1 \mathrm{MW}_{\text {th }}$ pilot plant and model validation," Fuel, vol. 127, pp. 13-22, 2014.

[3] B. Arias, M. E. Diego, J. C. Abanades, M. Lorenzo, L. Diaz, D. Martinez, J. Alvarez, and A. Sanchez, "Demonstration of steady state $\mathrm{CO}_{2}$ Capture in a $1.7 \mathrm{MW}_{\text {th }}$ calcium looping pilot," Int. J. Greenhouse Gas Control, vol. 18, pp. 237-245, 2013.

[4] M. H. Chang, C. M. Huang, W. H. Liu, W. C. Chen, J. Y. Cheng, W. Chen, S. Ouyang, C. H. Shen, and H. Y. Hsu, "Design and experimental investigation of calcium looping process for $3 \mathrm{~kW}_{\text {th }}$ and $1.9 \mathrm{MW}_{\text {th }}$ facilities," Chem. Eng. Technol, vol. 36, no. 9, pp. 1525-1532, 2013.

[5] M. H. Chang, W. C. Chen, C. M. Huang, W. H. Liu, Y. C. Chou, W. C. Chang, W. Chen, J. Y. Cheng, K. E. Huang, and H. W. Hsu, "Design and experimental testing of a $1.9 \mathrm{MW}_{\text {th }}$ calcium looping pilot plant," Energy Procedia, vol. 63, pp. 2100-2108, 2014.

[6] H. Lu, A. Khan, and P. G. Smirniotis, "Relationship between structural properties and $\mathrm{CO}_{2}$ capture performance of CaO-based sorbents obtained from different organometallic precursors," Ind. Eng. Chem. Res., vol. 47, pp. 6216-6220, 2008.

[7] W. Liu, N. W. Low, B. Feng, G. X. Wang, and J. C. Diniz Costa, "Calcium precursors for the production of $\mathrm{CaO}$ sorbents for multicycle $\mathrm{CO}_{2}$ capture,” Environ. Sci. Technol., vol. 44, pp. 841-847, 2010.

[8] C. Salvador, D. Lu, E. J. Anthony, and J. C. Abanades, "Enhancement of $\mathrm{CaO}$ for $\mathrm{CO}_{2}$ capture in an FBC environment," Chem. Eng. J., vol. 96, pp. 187-195, 2003.

[9] E. P. Reddy and P. G. Smirniotis, "High-temperature sorbents for $\mathrm{CO}_{2}$ made of alkali metals doped on CaO supports," J. Phy. Chem. B, vol 108, pp. 7794-7800, 2004. 
[10] W. Wang, S. Ramkumar, D. Wong, and L. S. Fan, "Simulations and process analysis of the carbonation-calcination reaction process with intermediate hydration," Fuel, vol. 92, pp. 94-106, 2012.

[11] Y. C. Chou, H. W. Hsu, J. Y. Cheng, M. H. Chang, W. H. Liu, and C. M Huang, "Enhancement of $\mathrm{CaO}$ recyclability for carbon capture by steam calcination and steam hydration," presented at the Proc. $28^{\text {th }}$ Conference of Controlling Technology for Air Pollutants, Kaohsiung, Taiwan, AIR-19, 2013

[12] Y. C. Chou, J. Y. Cheng, M. H. Chang, and H. W. Hsu, "Effects of $\mathrm{CaO}$ hydration on carbonation behavior in calcium looping carbon capture process," presented at the Proc. $32^{\text {th }}$ Conference of Controlling Technology for Air Pollutants, Taoyuan, Taiwan, AIR001, 2013.

[13] M. H. Chang, W. C. Chen, C. M. Huang, W. H. Liu, Y. C. Chou, W. C. Chang, W. Chen, J. Y. Cheng, K. E. Huang, and H. W. Hsu, "Design and experimental testing of a $1.9 \mathrm{MW}_{\text {th }}$ calcium looping pilot plant," Energy Procedia, vol. 63, pp. 2100-2108, 2014.

[14] D. P. Hanak and V. Manovic, "Calcium looping with supercritical $\mathrm{CO}_{2}$ cycle for decarbonisation of coal-fired power plant," Energy, vol. 102, pp. 343-353, 2016.

[15] Y. C. Chou, M. H. Chang, J. Y. Cheng, and H. W. Hsu, "Application of cascade cyclone calciner to sorbent regeneration in calcium looping carbon capture process," presented at the $26_{\text {th }}$ National Conference on Combustion and Energy, Hsinchu, Taiwan, 20, 2016.

[16] Y. C. Chou, W. C. Chen, C. M. Huang, W. H. Liu, and H. W. Hsu, "Study on sorbent calcination by 500kWt cascade cyclone calciner," presented at the 27th National Conference on Combustion and Energy, Taichung, Taiwan, 2017.

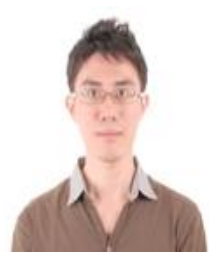

Y. C. Chou was born in Taiwan in 1982. He got his doctoral degree in chemical engineering from the National Taiwan University of Science and Technology. Dr. Chou works as researcher in Industrial Technology Research Institute in May 2012.

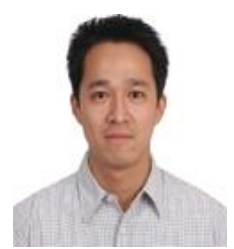

W. C. Chen was born in Taiwan in 1976. He got his master degree from the National Taiwan University. He works as senior researcher in Industrial Technology Research Institute.

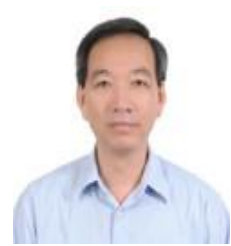

H. W. Hsu was born in Taiwan in 1960. He got his doctoral degree in chemical engineering from the National Tsing Hua University. He works as principal engineer in Industrial Technology Research Institute. Dr. Hsu is the principal investigator of the "Calcium Looping Technology" project.

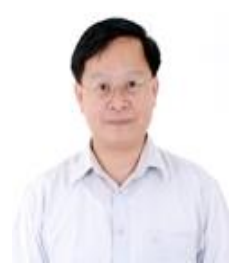

H. P. Wan got his doctoral degree in chemical engineering from the Chung Yuan Christian University. He works as principal researcher in Industrial Technology Research Institute, ITRI. He is the division director for the New Energy Technology Division in ITRI. Dr. Wan is also the principal investigator of the "Research and Demonstration for Carbon Capture and Storage Technology" project. 